¿Remember that Time is Money.

He that can earn Ten Shillings

a Day ... and ... sits idle one

half of that Day ... has really

... thrown away Five Shillings."

Benjamin Franklin, Papers (1961) III 306

„Unter dem Begriff 'Leben' in \$. 823 I BGB ist also außerdem noch die Lebenszeit zu verstehen, das wertvollste Gut, das der Mensch haben kann. Das ist erstaunlich, ja das Abstruse ist nun, daß ausgerechnet bei Verletzung dieses Gutes es keine Sanktion und keinen Schadensersatz geben soll, soweit man der herrschenden Lehre und Rechtsprechung folgt."

Sevold Braga, Der Mensch und seine Zeit. Zur Lebenszeit als Persönlichkeitsrecht i. S. des $\int 823$ $I B G B$, in: Verfassungsrecht und Völkerrecht. Gedächtnisschrift für Wilhelm Karl Geck, brsg. v. Wilfried Fiedler und Georg Ress, Köln/Berlin/Bonn/München 1989, S. 91-96, 92.

\title{
Time is (?) Money
}

Ein franzöșischer Philosoph soll gesagt haben, der Verstand sei das am besten verteilte Gut der Welt: Jeder meine, er habe genug davon. Mit dem Gut der Zeit sieht das völlig anders aus: Nahezu jeder meint, er habe nicht genug davon.

Die Angst, wegen schlechter Planung Zeit zu verschwenden, hat bereits im (reinen) „Papierzeitalter" Zeitplanungssystemen einen Markt eröffnet. Indessen stießen diese Hilfsmittel bald an ihre "medienbedingten” Grenzen: Wer eine Agenda (oder "To-Do”-Liste) in Papierform führt, kann diese in dieser Form nicht ökonomisch umsortieren. Wie stets beim Umordnen von Elementen rief das die EDV auf den Plan: Die elektronischen Zeitplanungssysteme folgten den papiergestützten - oft in nützlicher Symbiose mit dem Papiermedium. Denn trotz aller Defizite der papiergebundenen Fixierung: Unbestreitbare Vorteile bietet auch dieses Instrumentarium. Es ist handlich, leicht transportierbar, unaufwendig nutzbar (meist ohne Handbuch!). Umgekehrt weist auch das elektronische Terminmanagement (den Vorteilen des Papiers spiegelbildliche) Nachteile auf: Man benötigt ein relativ hohes Handhabungs-Know-how und ist an die Verfügbarkeit eines Apparats gebunden, der trotz aller Miniaturisierung noch nicht in brauchbarer Weise die Dimensionen (und die Dauerhaftigkeit!) eines kleinen Notizbuchs erreicht hat - von der Unaufwendigkeit des Notierens mit einem Bleistift ganz zu schweigen. Kurzum: Die „Koexistenz” von computergestütztem Zeitmanagement mit Papierumsetzungen hat einiges für sich. Sie ist übrigens unter Umständen sogar von der Rechtsprechung zur Anwaltshaftung her geboten. In eine derartige Richtung deuten beispielsweise die folgenden Ausführungen des LG Lübeck ^:

„Zunächst muß kontrolliert werden, ob die in der Handakte vermerkten Fristen überhaupt in den Computer eingegeben worden sind. Außerdem ist zu überprüfen, ob die gespeicherten Daten mit den schriftlich vermerkten Fristen übereinstimmen."

Die „schriftlich vermerkten Fristen” bilden demnach den dominanten Bezugspunkt und sorgen für die Richtigkeitsgewähr - die im Computer vermerkten Fristen sind im Vergleich dazu sekundär: „Quod non est in actis non est in mundo" (auch nicht rechtsbeständig in der elektronischen Welt).

Auch angesichts weiter notwendiger (und vielleicht sogar wünschenswerter) ParallelBuchführung in Papier kann diese Symbiose doch insgesamt Systemvorteile bieten, die einer der beiden Systemkomponenten allein versagt sind. Dementsprechend integrieren die beiden in diesem Heft näher analysierten Zeitplanungshilfen („ERNA” und „soft-use Termine”) in selbstverständlicher Weise die Möglichkeit des Ausdrucks und bestätigen so neben den durch ihre Existenz implizit behaupteten Vorteilen des Elektronischen die (für manche Handlungsaspekte gegebene) Unumgänglichkeit der papiergebundenen Fixierung (das LG Lübeck wäre sicherlich ganz einverstanden).

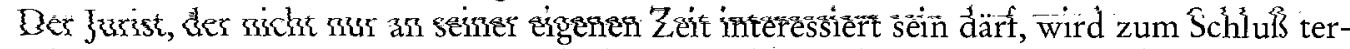
minplanorientierter Erwägungen gedanklich wieder zu der Frage zurückkehren, was ihm die Zeit (auch seiner Mitmenschen) juristisch wert ist. Kann jemand hier - auch nach geltendem Recht - als „Zeitdieb” in Erscheinung treten? Hören wir diesbezüglich noch einmal Sevold Braga:

„Wie aber kann ein Eingriff in die Lebenszeit eines anderen erfolgen, zumal die Zeit durch -ihr Wesen als Naturgesetz für alle gleich läuft und unentziehbar, daher unverletzlich, zu sein scheint ... Das täuscht, denn die Zeit verläuft zwar für alle gleich, jedoch soziologisch und anthropologisch hat jeder seine Zeit, seine höchst persönliche und verletzliche Lebenszeit. Man weiß aus der täglichen Erfahrung nur zu gut, daß die Möglichkeit, einem anderen Zeit 'zu stehlen' oder ihren normalen Ablauf zu hemmen, sogar sehr häufig besteht" (a. a. O.).

$\rightarrow$ Beschluß vom 28.3.1985, $6 S 49 / 85$, IuR 1986, S. 267

Gersweiler, den 22. Januar 1993

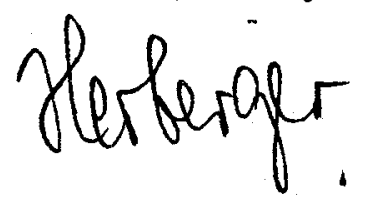

(Maximilian Herberger) 